\title{
APLICAÇÃO DE MÉTODO ELETROMAGNÉTICO TERRESTRE DE INVESTIGAÇÃO RASA NUMA OCORRÊNCIA CUPRÍFERA LOCALIZADA NO INTERIOR DO MUNICÍPIO DE CAÇAPAVA DO SUL (RS)
}

\author{
GROUND ELECTROMAGNETIC APPLICATION IN NEAR SURFACE INVESTIGATION OF A \\ COPPER MINERALIZATION IN THE CAÇAPAVA DO SUL COUNTRYSIDE (RS)
}

\author{
Jorge da Cruz BITENCOURT ${ }^{1}$, Henrique Garcia PEREIRA ${ }^{2}$, José Pedro Rebés LIMA ${ }^{1}$, \\ Marco Antonio Fontoura HANSEN ${ }^{1}$, César Augusto MOREIRA ${ }^{3}$ \\ ${ }^{1}$ Universidade Federal do Pampa - UNIPAMPA. Avenida Pedro Anunciação, 111, Caçapava do Sul, RS. \\ E-mails: jorge_cb.1987@hotmail.com; jprebes@unipampa.edu.br; marcohansen@unipampa.edu.br \\ ${ }^{2}$ Universidade Federal do Paraná - Avenida Coronel Francisco Heráclito dos Santos, 100, Curitiba, PR. \\ E-mail: ique_garcia@hotmail.com \\ ${ }^{3}$ Universidade Estadual Paulista Júlio de Mesquita Filho - Avenida 24-A, 1.515, Rio Claro, SP. \\ E-mail: cesar.a.moreira@unesp.br

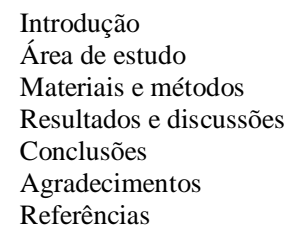

RESUMO - O atendimento e manutenção de demandas industriais e de construção civil em relação a insumos minerais estimula pesquisas para a descoberta de novos depósitos minerais ou para a ampliação de jazidas conhecidas. O método geofísico eletromagnético indutivo (EM) é muito utilizado em estudos envolvendo a pesquisa de minerais metálicos. Na busca por cobre o método EM é eficiente devido a este metal se comportar como excelente corpo condutor na presença de um campo magnético, o que por sua vez possibilita a sua distinção dos demais constituintes rochosos pela elevada condutividade elétrica resultante. Este trabalho descreve a aplicação do método EM para mapeamento de fraturas mineralizadas na área da ocorrência cuprífera Victor Teixeira. A investigação da subsuperfície foi elaborada de acordo com o alinhamento tectônico preferencial NW-SE das fraturas mineralizadas obtidas previamente pelos dados de sensoriamento remoto e corroborada pelas atitudes obtidas no levantamento estrutural de detalhe. As seções de condutividade aparente evidenciaram anomalias verticais de elevada condutividade (superiores a $15 \mathrm{mS} / \mathrm{m}$ ) para os locais onde cruzavam as fraturas mapeadas, sugerindo a confirmação da presença de mineralizações cupríferas em subsuperfície na área da ocorrência mineral estudada.

Palavras-chave: Método eletromagnético, Sensoriamento remoto, Cobre.

\begin{abstract}
The service and maintenance of industrial and civil construction demands in relation to mineral inputs stimulates research to the discovery of new mineral deposits or the expansion of known deposits. The inductive electromagnetic geophysical method (EM) is widely used in studies involving the research of metallic minerals. In the search for copper the EM method is efficient because this metal behaves as an excellent conductor body in the presence of a magnetic field, which enables the distinction it from other rocky constituents by resulting high electric conductivity. This paper describes the application of the EM method for the mapping of mineralized fractures in the area of the Victor Teixeira cupper occurrence. The subsurface investigation was elaborated according to the preferred NW-SE tectonic alignment of the mineralized fractures previously obtained by the remote sensing data and supported by the attitudes obtained in the detail structural survey. The apparent conductivity sections showed high conductivity vertical anomalies (greater than $15 \mathrm{mS} / \mathrm{m}$ ) to the locations where crossed the mapped fractures, suggesting the confirmation of the presence of subsurface copper mineralization in the area of the mineral occurrence studied.
\end{abstract}

Keywords: Electromagnetic method, Remote sensing, Copper.

\section{INTRODUÇÃO}

O principal objetivo de estudos envolvendo a pesquisa mineral consiste na descoberta de novas jazidas, além do detalhamento ou da reavaliação de depósitos conhecidos. A descoberta ou a reavaliação de jazidas minerais envolve uma série de métodos de investigações geológicas diretas e indiretas (Pereira, 2003).

Investigações diretas compreendem amostragens de solo, rocha e águas para análises químicas, assim como a abertura de poços, trincheiras e furos de sondagens. As investigações indiretas são baseadas no contraste de propriedades físicas intrínsecas aos materiais geológicos, representados basicamente pelo sensoriamento remoto e pela geofísica aplicada (Moon et al., 2006).

De acordo com Bizzi et al. (2003), a interpretação de feições representadas em imagens de sensoriamento remoto permite o mapeamento e a identificação de áreas com 
recursos minerais e até mesmo a identificação entre a rocha hospedeira do minério e a rocha encaixante, bem como a produção de mapas geológicos, levantamentos estruturais e a identificação do relevo da região estudada.

Os métodos geofísicos mais utilizados na pesquisa mineral são a eletrorresistividade e a polarização induzida, seguidos dos eletromagnéticos, da magnetometria e da gravimetria (Kearey et al., 2002).

O método Eletromagnético Indutivo (EM) é comumente utilizado em estudos envolvendo a busca de metais base. O sucesso do emprego do método ocorre normalmente pelo contraste de propriedades físicas obtidas entre os minerais metálicos condutivos e a rocha encaixante (Telford et al., 1990).

O presente trabalho apresenta e discute os dados da aplicação do método EM, com base em imagens de sensoriamento remoto, em pesquisa desenvolvida para o mapeamento de zonas fraturadas com possíveis mineralizações de cobre em subsuperfície na área de ocorrência cuprífera denominada Victor Teixeira.

\section{ÁREA DE ESTUDO}

A área de estudo está situada a noroeste da sede do município de Caçapava do Sul, que pertence a porção central do estado do Rio Grande do Sul. O município fica a $259 \mathrm{~km}$ da capital Porto Alegre pela BR 290. Apresenta população de 34634 habitantes e tem sua economia baseada na pecuária, agricultura e mineração (IBGE, 2018).
$\mathrm{O}$ acesso à área de estudo partindo da cidade de Caçapava do Sul é realizado pela BR 392, por 17 $\mathrm{km}$ até o viaduto da BR 290, onde é acessada para oeste, por $15 \mathrm{~km}$ até a vila Cerrito do Ouro. Nesta localidade, toma-se a estrada municipal Lavras do Sul - São Sepé para o sul, por $11 \mathrm{~km}$ até a área de estudo (Figura 1).

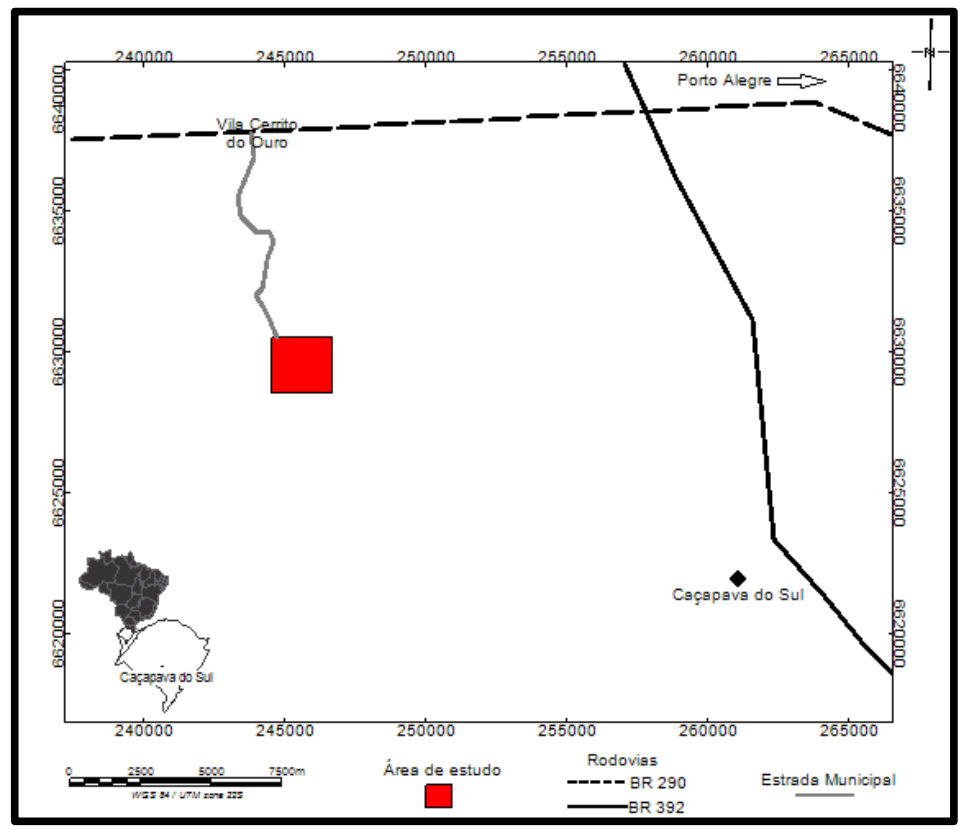

Figura 1 - Localização da área de estudo.

$\mathrm{Na}$ área de estudo ocorrem rochas metavulcanoclásticas do Complexo Metamórfico Vacacaí, unidade integrante do Escudo Sul-RioGrandense, recobertas pelas unidades vulcanossedimentares pertencentes à Bacia do Camaquã, representadas pelas formações Passo da Promessa, Arroio América e Acampamento Velho (Figura 2). A ocorrência cuprífera Victor Teixeira está inserida no contexto da unidade metavulcanoclástica do Complexo Metamórfico Vacacaí. De acordo com Porcher et al. (1995), predominam rochas vulcanoclásticas, as quais se associam a rochas epiclásticas e químicas, que foram afetadas pelo contato com rochas supracrustais, cujo metamorfismo gerou condições de fácies xisto verde inferior, zona da clorita.

Vestígios de fácies metamórficas mais elevadas, geradas por metamorfismos de contato, também são registradas, como hidrotermalismo, silicificação e carbonatização, responsáveis pelas fácies hornblenda hornfels, impostos principalmente por intrusões graníticas brasilianas pós-tectônicas mais jovens (Porcher et al., 1995).

$\mathrm{O}$ afloramento mineralizado que constitui a ocorrência Victor Teixeira apresenta em superfície 
$5 \mathrm{~m}$ de comprimento por $2 \mathrm{~m}$ de largura, segundo a direção NE (Figura 3a).

É constituído por rochas com foliação plano paralela e coloração que varia de cinza esverdeado a cinza escuro, respectivamente clorita-xistos e actnolita-xistos, que apresentam algumas impregnações de malaquita entre os espaços das foliações (Figura 3b).

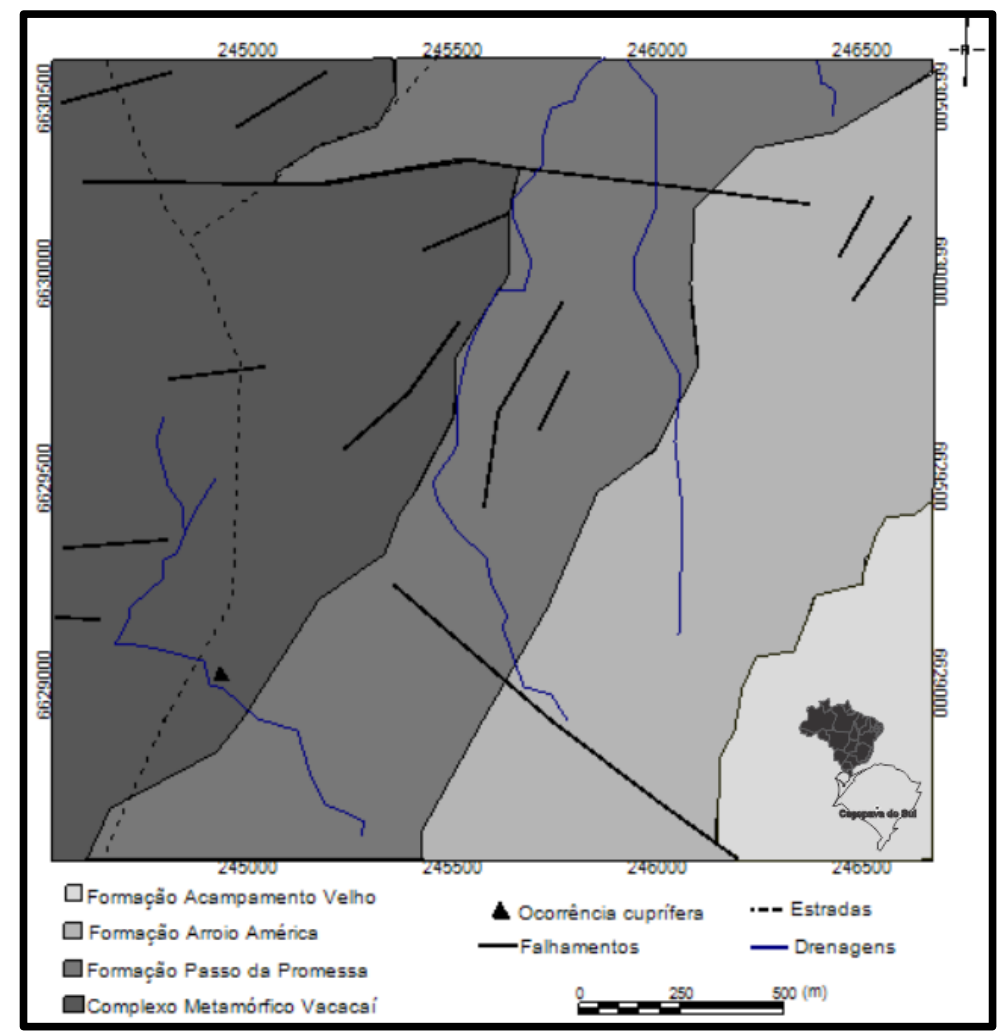

Figura 2 - Litologia e ocorrência mineral (Adaptado de Porcher et al., 1995).

O afloramento faz parte de um bloco de quartzo de direção W-E que se destaca no relevo (Figura 3c).

Nas proximidades da ocorrência mineralizada em cobre Victor Teixeira ocorrem afloramentos de riolitos cinza-amarronzados a cinza-avermelhados, intensamente fraturados, pertencentes à Formação Acampamento Velho (Figura 4).

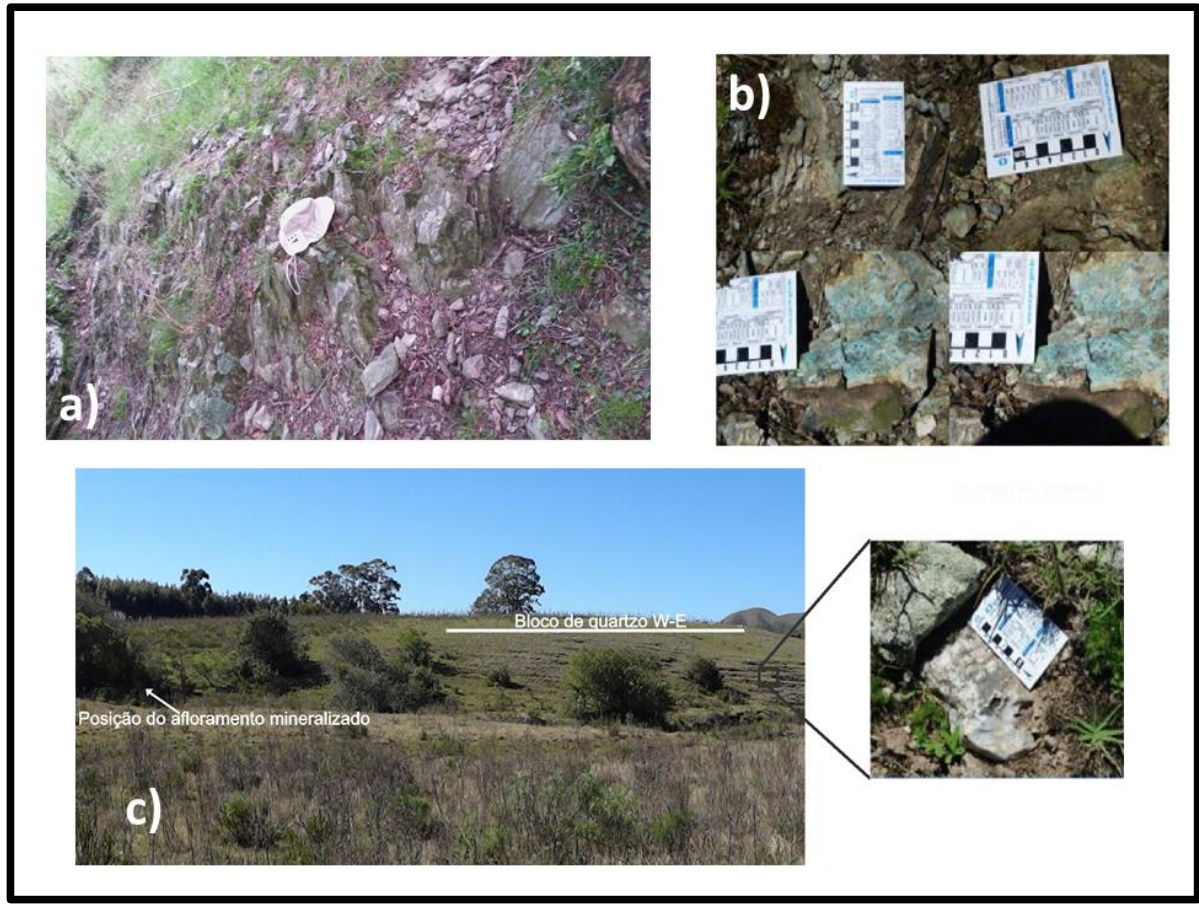

Figura 3 - Características do afloramento mineralizado com malaquita: a) disposição NE; b) carbonatos em xistos; c) bloco de quartzo W-E. 


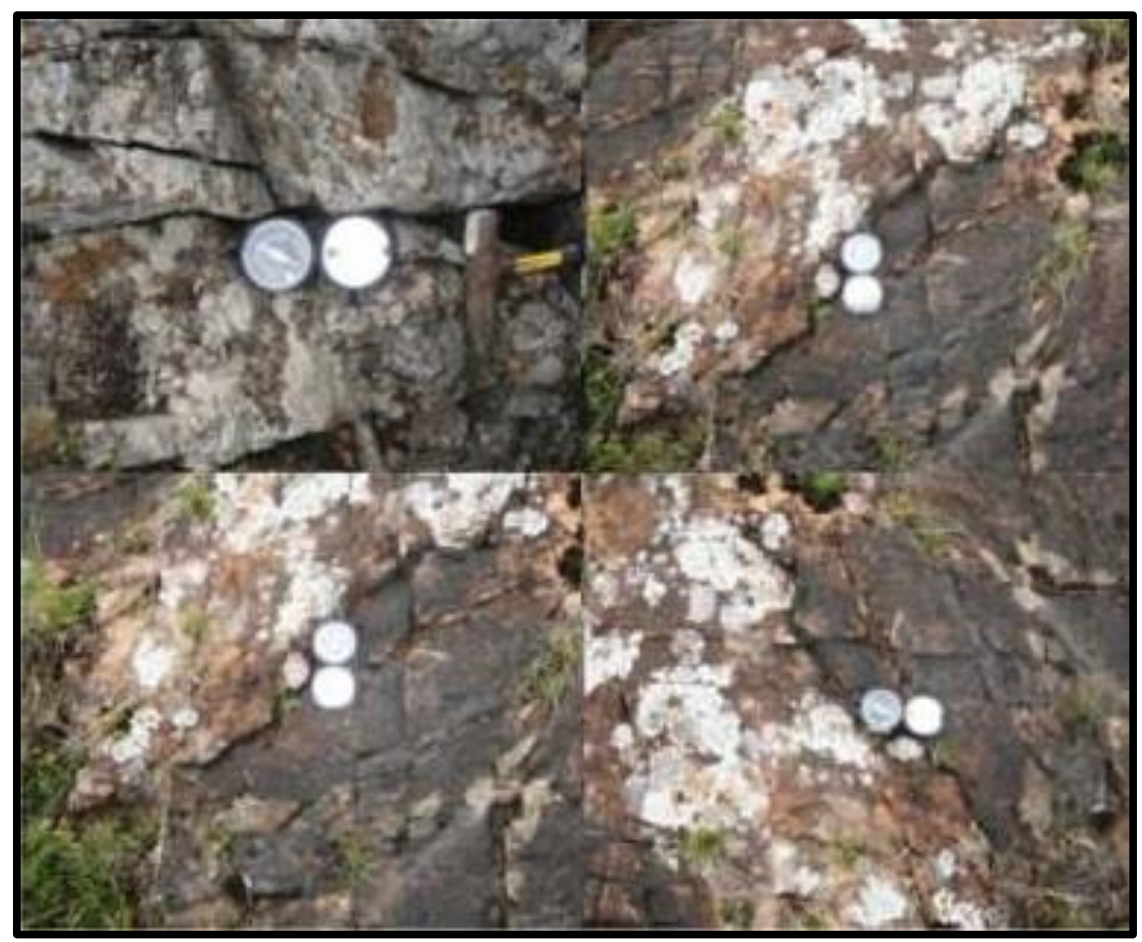

Figura 4 - Riolitos intensamente fraturados.

\section{MATERIAIS E MÉTODOS}

O método eletromagnético indutivo (EM) utilizado determina a condutividade aparente $(\sigma)$ dos materiais em subsuperfície a partir da técnica de número de indução baixo (Benson \& Stubben, 1995).

A principal vantagem deste método consiste na facilidade com que as medidas podem ser tomadas, devido à versatilidade do equipamento em campo e a possibilidade de varredura de grandes áreas num curto espaço de tempo, diminuindo os custos do levantamento (EPA, 1993; Goldstein et al., 1990).
Maiores informações quanto aos princípios teóricos do método EM, propriedades físicas dos materiais geológicos, assim como os principais fenômenos físicos envolvidos são descritos em Telford et al. (1990), Kearey et al. (2002), McDowell et al. (2002), Milsom (2003) e Knödel et al. (2007).

$\mathrm{O}$ equipamento utilizado no estudo foi o condutivímetro de terreno EM-34, modelo XL, da Geonics Ltda. (Figura 5), adquirido por meio de edital de apoio a pesquisa pela Pró-Reitoria de Pesquisa, Pós-Graduação e Inovação da Universidade Federal do Pampa - UNIPAMPA.

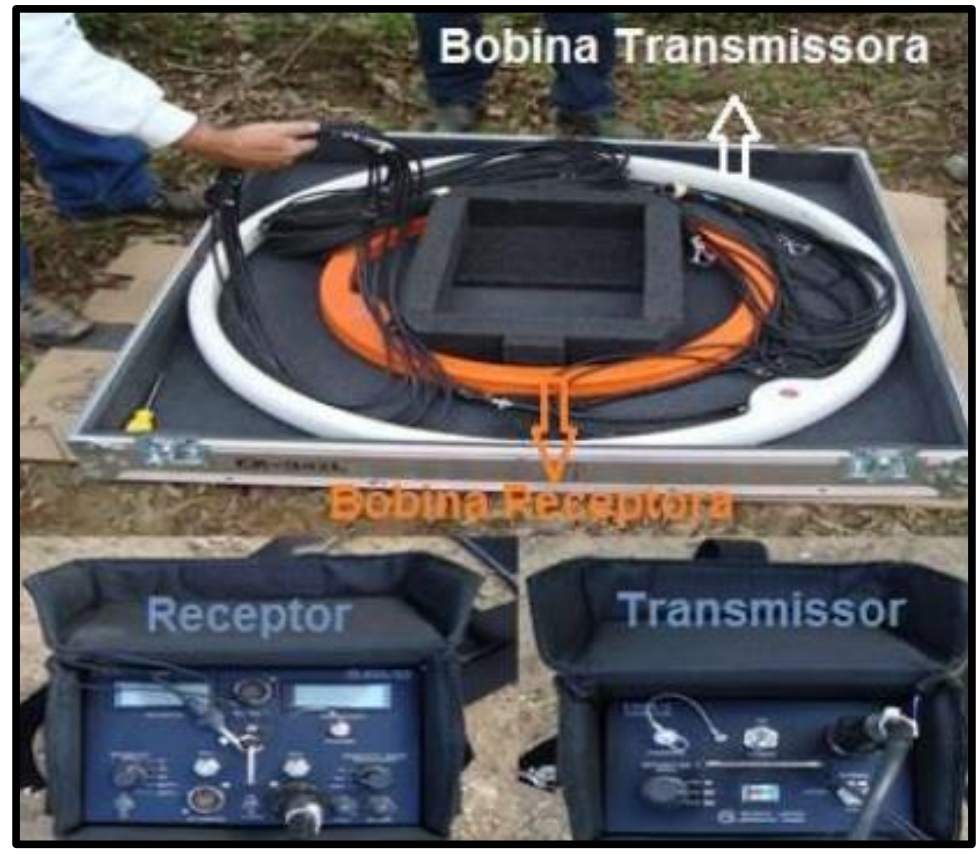

Figura 5 - Equipamento EM34 modelo XL. 
O equipamento EM-34 permite a leitura direta da condutividade aparente em subsuperfície. $\mathrm{O}$ princípio de funcionamento do aparelho decorre da passagem de corrente elétrica alternada por meio de uma bobina transmissora Tx (bobina branca - Figura 5), responsável pela indução de um campo magnético primário $\mathrm{Hp}$, que ao propagar-se em um meio condutor no subsolo, induz correntes elétricas secundárias alternadas, que induzem um campo magnético secundário Hs. O campo magnético secundário $\mathrm{H} s$ é percebido, juntamente com o campo magnético primário $\mathrm{H} p$, na bobina receptora $\mathrm{Rx}$ (bobina laranja - Figura 5). A razão entre os campos $\mathrm{H} p$ e $\mathrm{H} s$ no receptor é linearmente proporcional a condutividade aparente $\sigma_{a}$, sendo expressa por:

$$
\sigma_{a}=\frac{4}{\omega \mu_{0} s^{2}}\left(\frac{H s}{H p}\right)
$$

onde:

$\sigma_{a}=$ condutividade aparente $(\mathrm{mho} / \mathrm{m})$

Hs = campo magnético secundário

$\mathrm{Hp}$ = campo magnético primário

$\omega=2 \pi f$

$\mathrm{F}=$ frequência $(\mathrm{Hz})$

$\mu_{0}=$ permeabilidade do espaço livre $(\mathrm{H} / \mathrm{m})$

e $s$ é a separação entre as bobinas, (m) (McNeill, 1980).
, em siemens por metro; $f$ é a frequência em hertz; $\mu$ é a permeabilidade magnética, em hertz por metro; e $s$ é a separação entre as bobinas, em metros (McNeill, 1980).

$\mathrm{O}$ intervalo de condutividade aparente registrado varia de 0 a $1000 \mathrm{mS} / \mathrm{m}$. O nível de ruído do equipamento é de $0,2 \mathrm{mS} / \mathrm{m}$. A precisão da medida é de $\pm 2 \%$ da deflexão da escala completa. As frequências de operação variam conforme o espaçamento entre as bobinas. Funciona entre temperaturas de $-40^{\circ} \mathrm{C}$ até $+50^{\circ} \mathrm{C}$, fora destes parâmetros de temperaturas pode apresentar erros nas leituras e até mesmo nem funcionar (Geonics, 2007).

O EM 34 foi aplicado ao longo de sete perfis de caminhamento eletromagnético (Greenhouse \& Slaine, 1986): cinco perfis dispostos segundo a direção NE-SW (B1, B2, B3, B4, B5) e dois NS A1 e A2 (Figura 6).

Os perfis NE-SW foram definidos de acordo com uma análise prévia da direção NW preferencial dos lineamentos tectônicos obtidos por processamento de imagens INPE (Instituto Nacional de Pesquisas Espaciais), do satélite LANDSAT 5-TM (Figura 7). Os lineamentos foram retirados através da banda 5 e o processamento foi realizado por meio do software SPRING, versão 4.2.

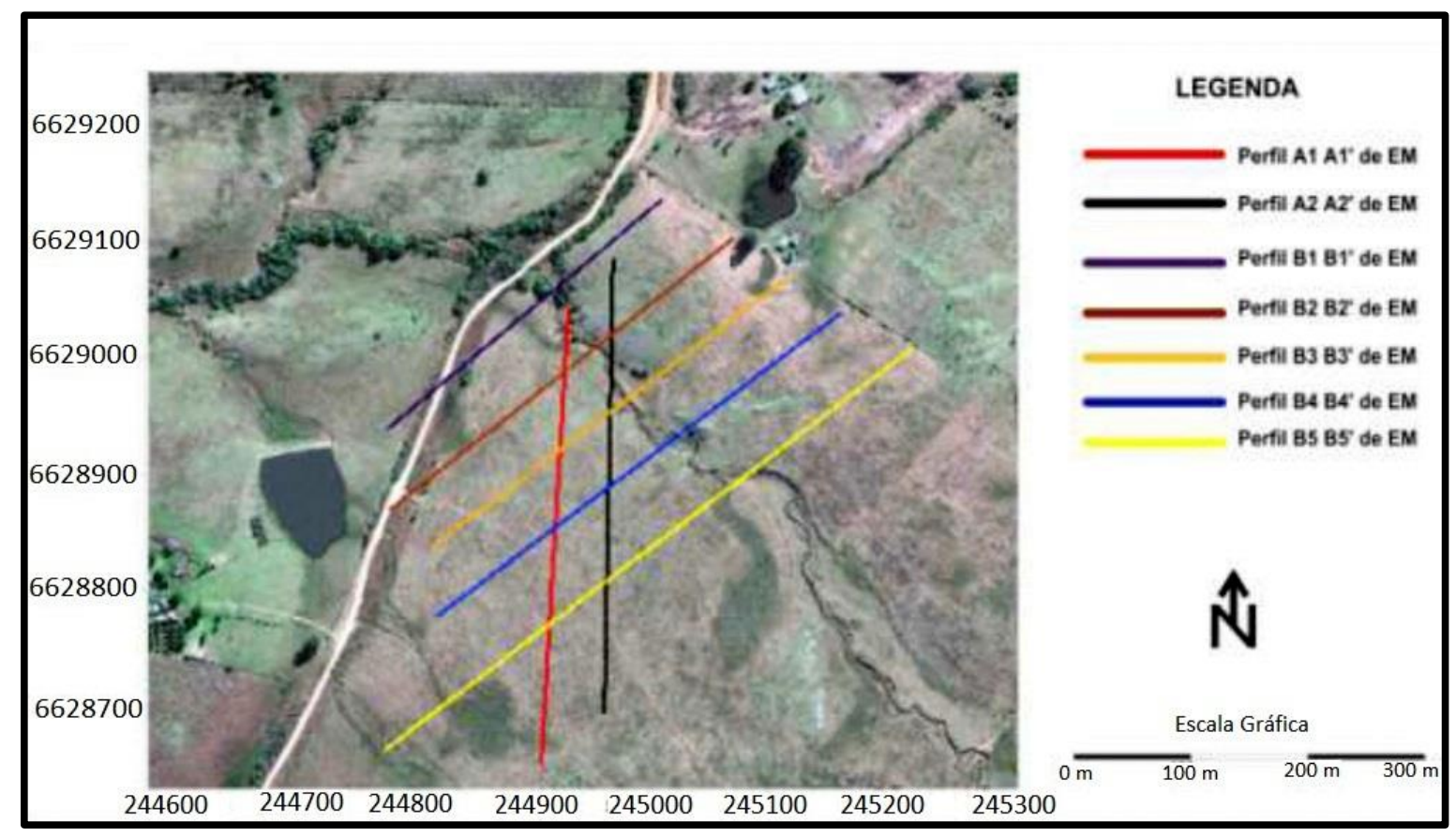

Figura 6 - Croqui de localização dos perfis de caminhamento eletromagnético.

A direção preferencial NW observada nos lineamentos tectônicos obtidos por sensoriamento remoto foi corroborada no levantamento estrutural de detalhe (Figura 8). Os perfis A1 e A2 foram realizados para critério de comparação.

Os perfis foram elaborados com comprimentos variados (entre $370 \mathrm{~m}$ e $500 \mathrm{~m}$ ) e 
em equidistância de $50 \mathrm{~m}$. Em cada perfil foram tomadas medidas de condutividade aparente a cada $10 \mathrm{~m}$, com os dipolos posicionados na vertical (modo Dipolo Horizontal) e na horizontal (modo Dipolo Vertical) e com cabos de $10(6400 \mathrm{~Hz}), 20(1600 \mathrm{~Hz})$ e $40 \mathrm{~m}(400 \mathrm{~Hz})$, permitindo a investigação atingir $60 \mathrm{~m}$ de profundidade. Os dados adquiridos nos caminhamentos eletromagnéticos foram processados no software Surfer, desenvolvido pela Golden Software Inc. O Surfer é um pacote de programas gráficos, que pode ser utilizado para o cálculo e a confecção de seções e mapas de variáveis a partir da interpolação de dados regularmente distribuídos (Golden Software Inc., 2009). O algoritmo de interpolação utilizado foi o de krigeagem, que utiliza distâncias ponderadas e estimação por médias móveis, pelo qual os pesos adequados são obtidos a partir de um variograma (Landim, 2000).

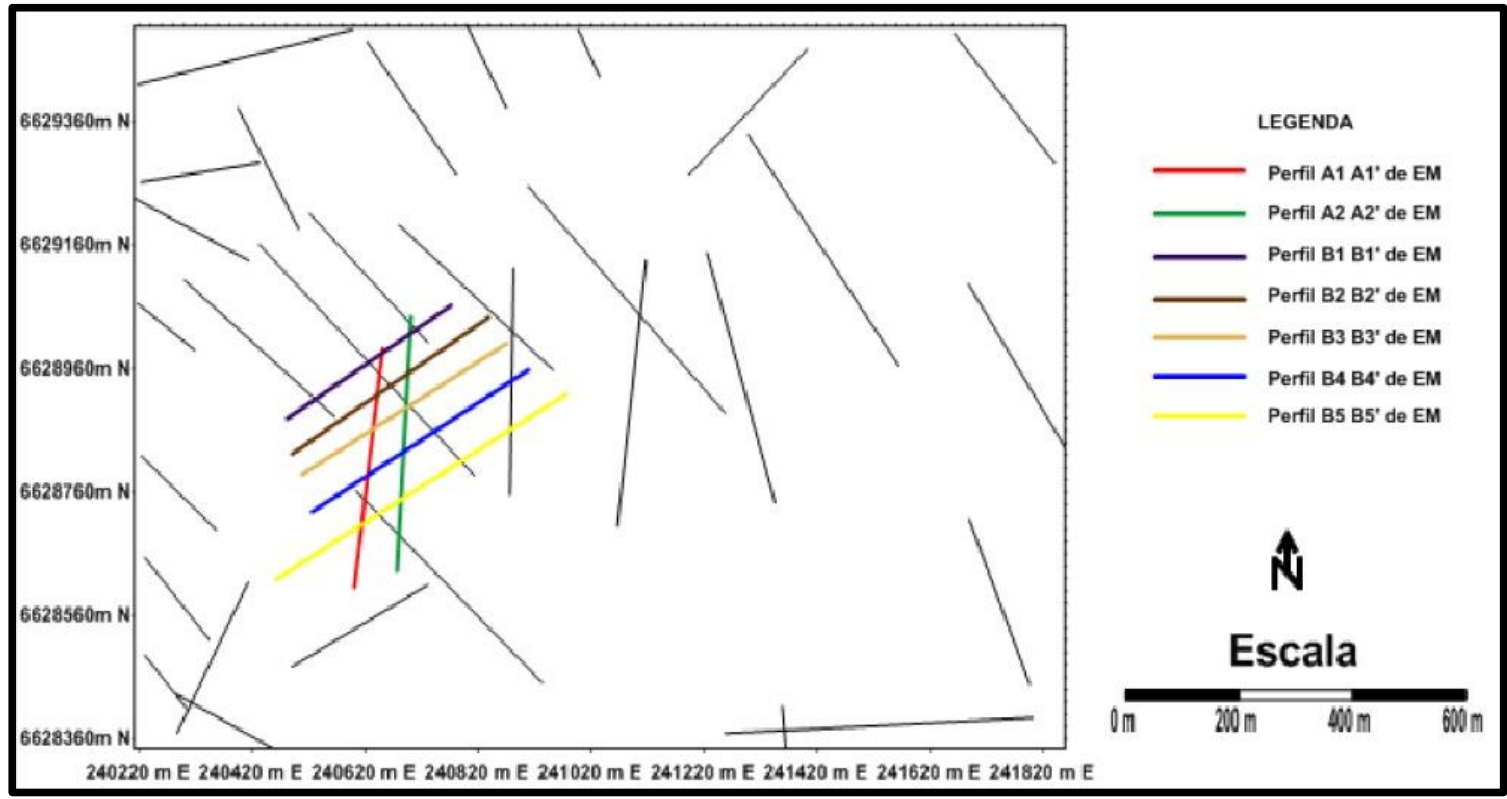

Figura 7 - Direções preferencias dos lineamentos tectônicos (traços em preto) obtidos por sensoriamento remoto com os perfis de caminhamento eletromagnético.

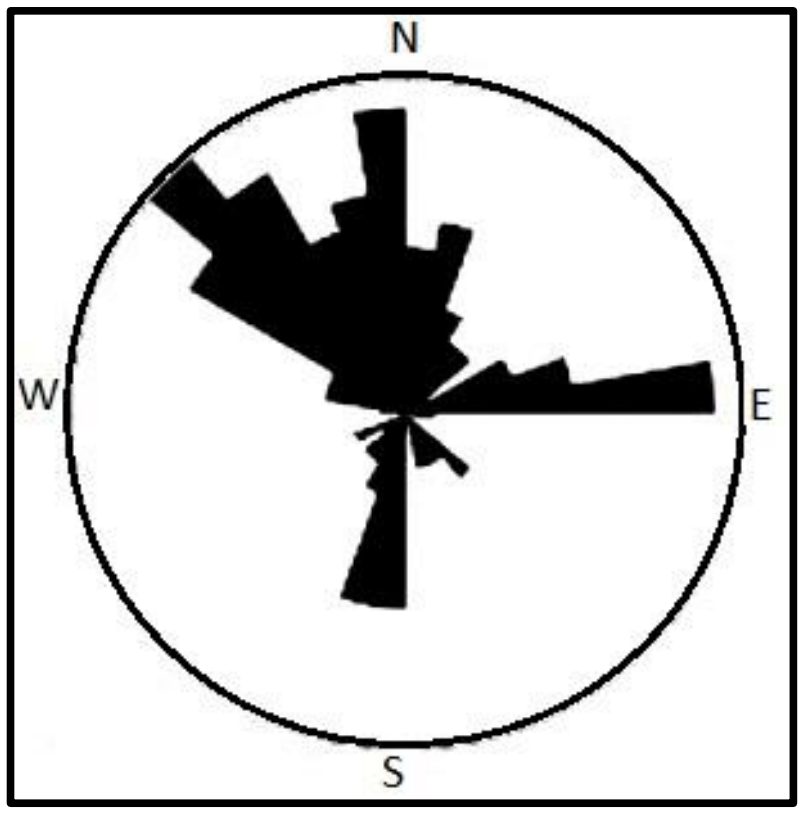

Figura 8 - Atitudes do levantamento estrutural de detalhe.

\section{RESULTADOS E DISCUSSÕES}

Os dados de condutividade aparente processados são apresentados sob a forma de pseudo-seções, com distância em superfície e profundidade em metros (Figuras 9, 10, 11, 12, 13, 14 e 15).

As pseudo-seções de condutividade aparente 
tiveram suas respostas padronizadas em escala única de cores e valores para que pudessem ser realizadas análises comparativas entre os perfis. Intervalos considerados de baixa condutividade são menores do que $7 \mathrm{mS} / \mathrm{m}$, intervalos de média condutividade estão entre $8 \mathrm{mS} / \mathrm{m}$ e $14 \mathrm{mS} / \mathrm{m}$ e valores elevados de condutividade são superiores a $15 \mathrm{mS} / \mathrm{m}$. A pseudo-seção de condutividade aparente do perfil N-S A1 foi caracterizada basicamente por uma primeira metade resistiva contrastante com uma porção final condutiva (Figura 9 - painel superior).

O perfil A1 cruza por dois lineamentos tectônicos NW-SE de acordo com a análise da imagem obtida por sensoriamento remoto (Figura 9 - painel inferior): um mais a norte, na estação de
$50 \mathrm{~m}$, e a outro mais a sul, na posição de $280 \mathrm{~m}$.

$\mathrm{Na}$ estação de $50 \mathrm{~m}$ foi caracterizada uma pequena anomalia vertical de fraco sinal no contexto da porção mais resistiva da seção. Esse lineamento tectônico é o mesmo que caracteriza o afloramento mineralizado. $\mathrm{O}$ lineamento que cruza a estação de $280 \mathrm{~m}$ foi demarcado por uma anomalia vertical condutiva (Figura 9 - painel superior).

A distribuição de condutividade aparente da pseudo-seção do perfil N-S A2 (Figura 10 painel superior) mostra um comportamento anômalo muito semelhante ao observado na pseudo-seção do perfil A1(vide Figura 9 - painel superior). A porção inicial resistiva da pseudoseção do perfil A2 foi atenuada e a porção final condutiva foi realçada.

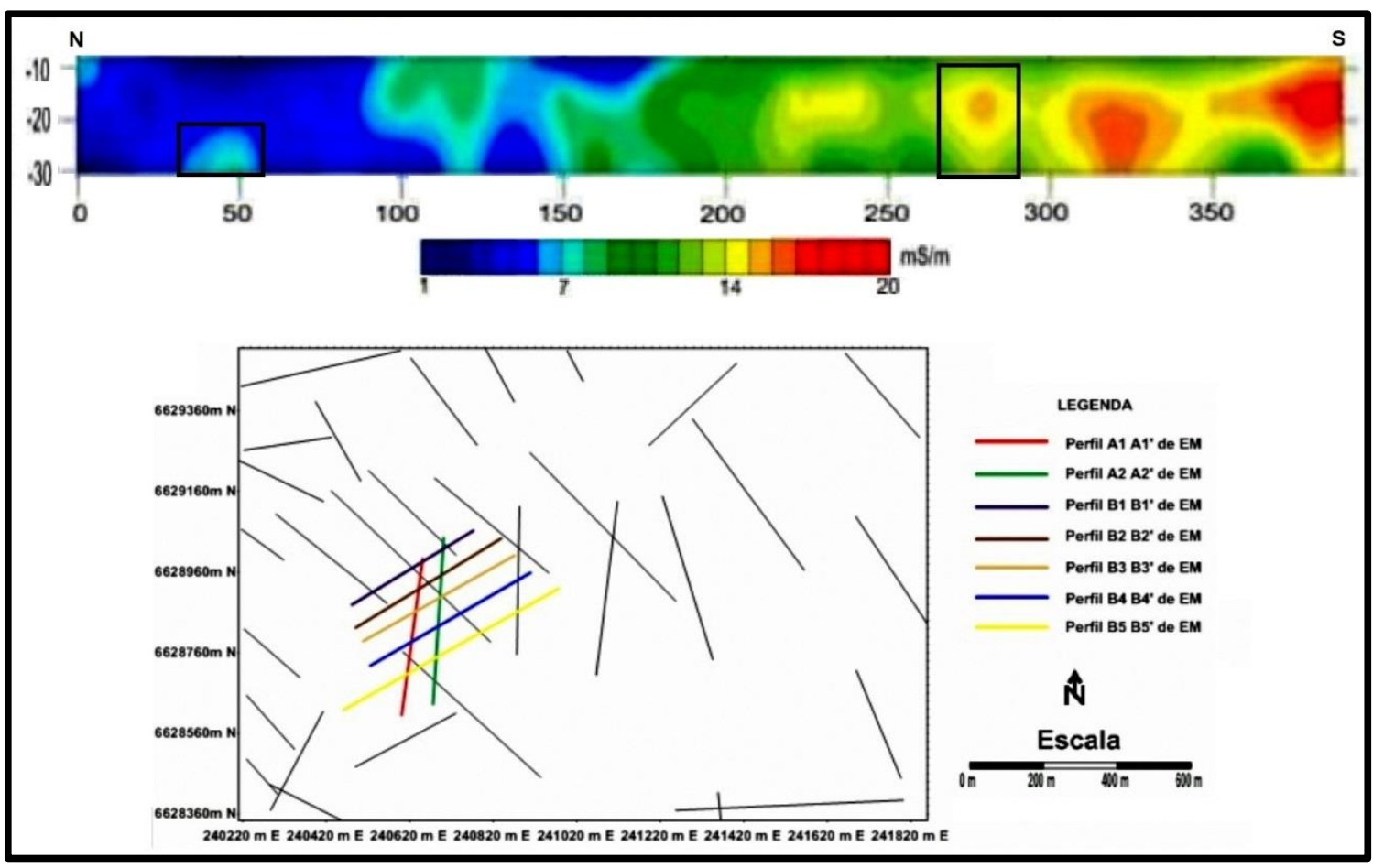

Figura 9 - Pseudo-seção de condutividade aparente do perfil A1 - painel superior; Lineamentos obtidos por sensoriamento remoto com os perfis EM - painel inferior.

O perfil A2 atravessa três lineamentos tectônicos NW-SE observados na imagem de satélite (Figura 10 - painel inferior): o primeiro mais a norte, na estação de $35 \mathrm{~m}$, outro próximo ao centro, na estação de $155 \mathrm{~m}$, e o último em $350 \mathrm{~m}$.

Em $35 \mathrm{~m}$ ocorre uma anomalia vertical de fraco sinal e média condutividade em meio à anomalia resistiva. O próximo lineamento localizado em $155 \mathrm{~m}$ é o que corresponde ao afloramento mineralizado. Neste local ocorre uma anomalia condutiva de fraco sinal. Já em 350 m ocorre uma anomalia vertical de elevada condutividade aparente e forte sinal (Figura 10 - painel superior).

A pseudo-seção de condutividade aparente do perfil NE-SW B1 foi demarcada por valores condutivos mais próximos à superfície em contraste com valores resistivos na base (Figura 11 - painel superior).

Os valores condutivos rasos se restringiram aos primeiros $30 \mathrm{~m}$ da subsuperfície como camadas horizontais. Associadas a essas anomalias horizontais aparecem duas anomalias verticais condutivas que atingem a base da seção, atravessando a anomalia resistiva (Figura 11 painel superior).

$\mathrm{O}$ perfil B1 passa por três lineamentos tectônicos NW-SE obtidos pela imagem de satélite (Figura 11 - painel inferior): o primeiro mais a NE, na estação correspondente a $50 \mathrm{~m}$, outro na estação de $115 \mathrm{~m}$, e o último bem a $\mathrm{SW}$, 
respectivamente na estação de $215 \mathrm{~m}$.

Em $50 \mathrm{~m}$ os valores de condutividade são resistivos. As posições de $115 \mathrm{~m}$ e $215 \mathrm{~m}$ correspondem às anomalias verticais condutivas que atingem a base da seção. O lineamento tectônico mineralizado que caracteriza a ocorrência cuprífera ocorre na posição de $115 \mathrm{~m}$ (Figura 11 - painel superior).

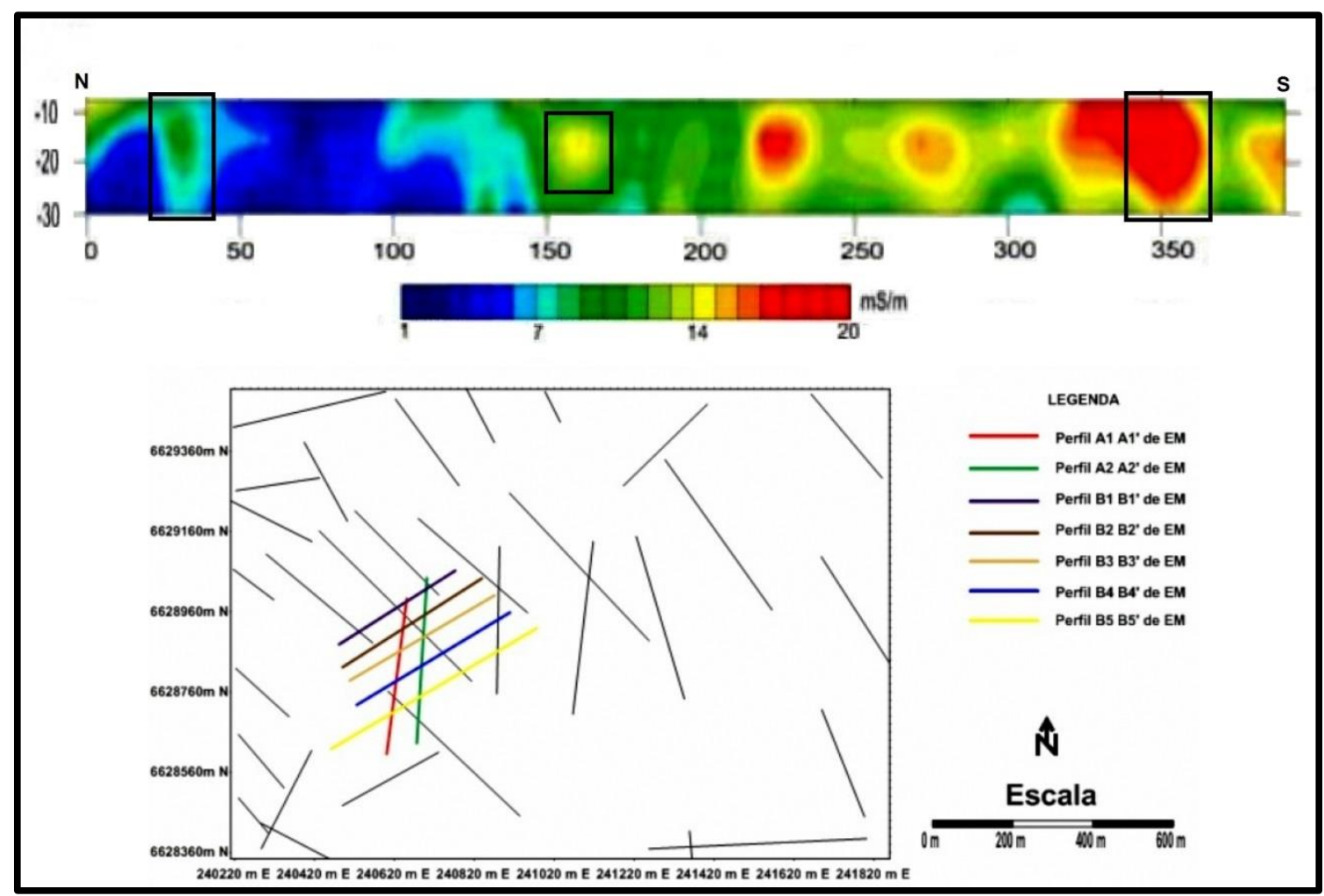

Figura 10 - Pseudo-seção de condutividade aparente do perfil A2 - painel superior; Lineamentos obtidos por sensoriamento remoto com os perfis EM - painel inferior.

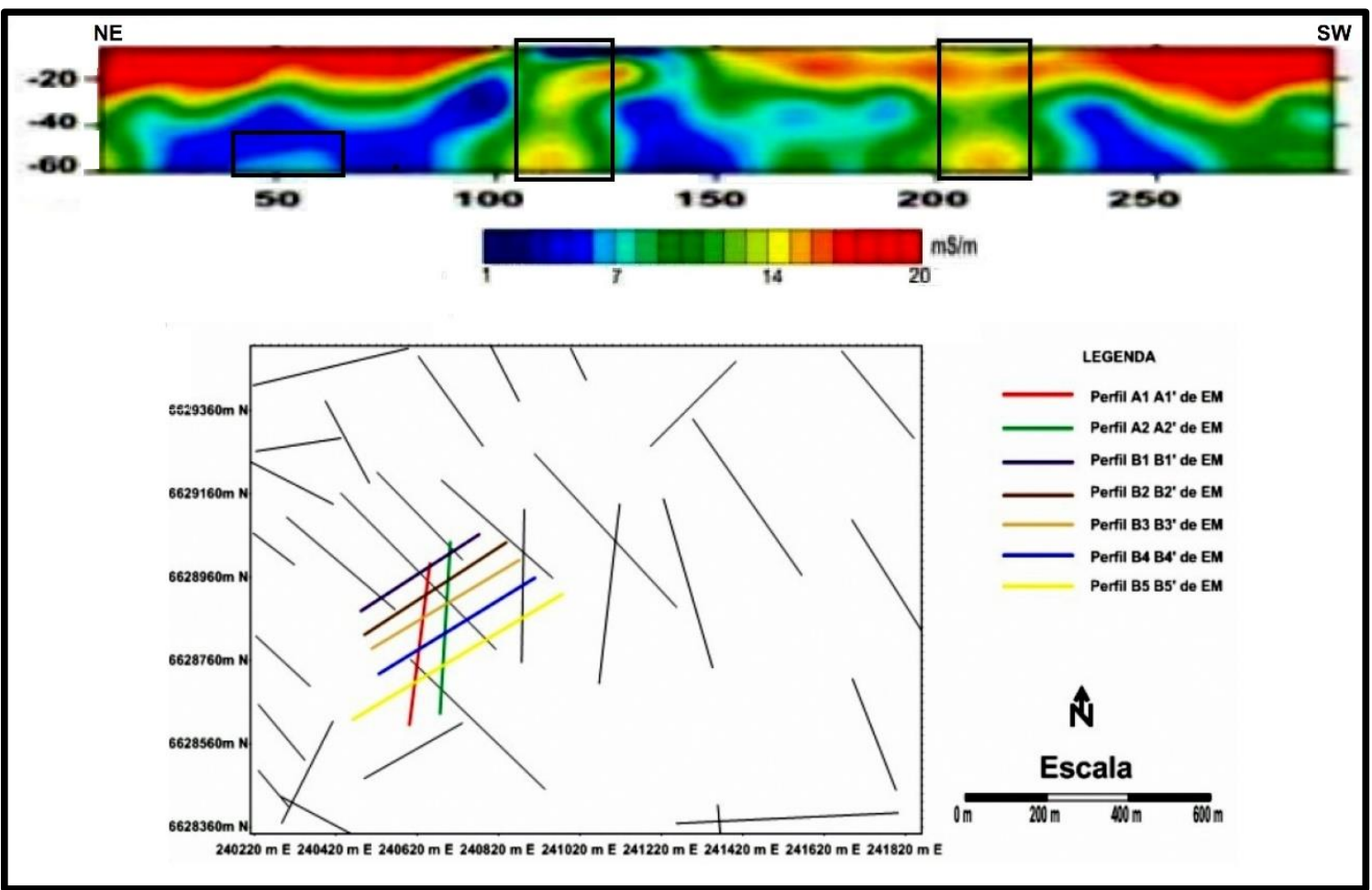

Figura 11 - Pseudo-seção de condutividade aparente do perfil B1- painel superior; Lineamentos obtidos por sensoriamento remoto com os perfis EM - painel inferior.

A distribuição de condutividade aparente da por uma faixa central resistiva com extremidades pseudo-seção do perfil NE-SW B2 é demarcada condutivas (Figura 12 - painel superior). 
$\mathrm{O}$ perfil B2 cruza apenas um lineamento tectônico de direção NW-SE na estação de 190 $\mathrm{m}$, referente à ocorrência do afloramento mineralizado (Figura 12 - painel inferior). Nesse local ocorre uma anomalia de média condutividade no contexto da anomalia resistiva (Figura 12 - painel superior).

A anomalia vertical condutiva de fraco sinal em $300 \mathrm{~m}$ deve representar a continuidade lateral para sudeste do lineamento de direção NW-SE que atravessa o perfil B1 mais a sudoeste, em 215 $\mathrm{m}$ (quadrado demarcado no painel inferior da Figura 12).

A pseudo-seção de condutividade aparente do perfil NE-SW B3 (Figura 13 - painel superior) apresenta comportamento anômalo muito semelhante ao observado na seção do perfil B2 (vide Figura 12 - painel superior).

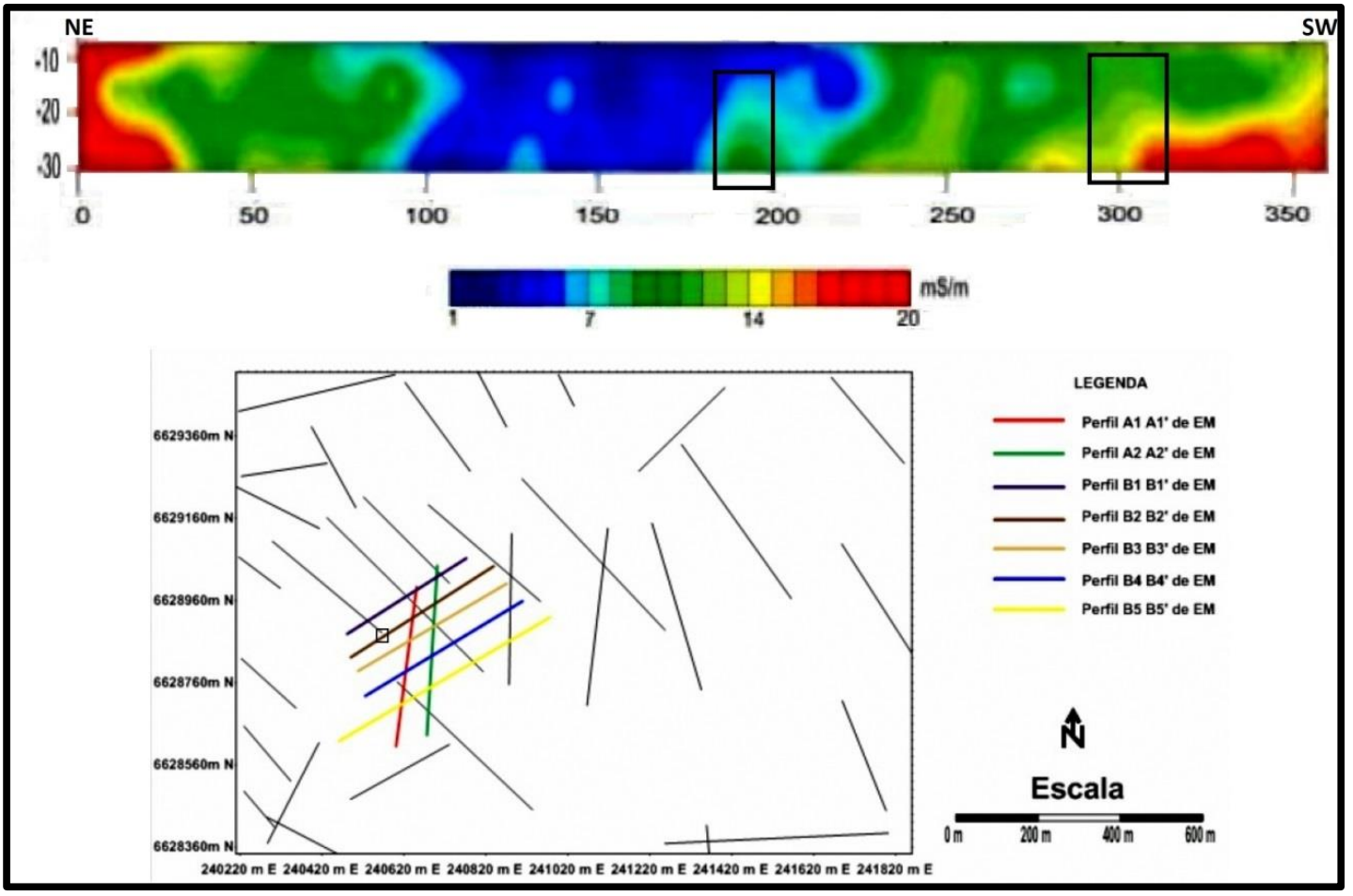

Figura 12 - Pseudo-seção de condutividade aparente do perfil B2 - painel superior; Lineamentos obtidos por sensoriamento remoto com os perfis EM - painel inferior.

Os primeiros $100 \mathrm{~m}$ da pseudo-seção do perfil B3 são mais condutivos e alcançam a base do perfil. A faixa central resistiva foi realçada até $250 \mathrm{~m}$. Dessa estação até o final do perfil os valores de condutividade decaíram (Figura 13 painel superior).

$\mathrm{O}$ perfil B3 também atravessa apenas pelo lineamento tectônico NW-SE correspondente ao afloramento mineralizado em $150 \mathrm{~m}$ (Figura 13 painel inferior). Nessa posição ocorre uma pequena anomalia de fraco sinal em meio à anomalia resistiva (Figura 13 - painel superior).

A anomalia vertical condutiva próxima à estação zero (Figura 13 - painel superior) parece indicar a resposta do lineamento N-S localizado próximo ao perfil (ver quadrado NE demarcado no painel inferior da Figura 13).

O comportamento condutivo observado em $275 \mathrm{~m}$ pode ser o resultado de uma provável continuidade para sudeste da fratura NW-SE que cruza B1 em 215 m e supostamente B2 em 300 m (ver quadrado SW demarcado no painel inferior da Figura 13).

A distribuição de condutividade aparente da pseudo-seção do perfil NE-SW B4 (Figura 14 painel superior) ainda é semelhante às respostas obtidas nas pseudo-seções dos perfis B2 e B3 (vide Figuras 12 e 13 - painéis superiores).

A anomalia central resistiva da pseudo-seção do perfil B4 teve sua porção mais rasa atenuada, enquanto que as anomalias condutivas das extremidades foram realçadas, se dispondo desde a superfície até a base da seção com valores altamente condutivos (Figura 14 - painel superior).

O perfil B4 passa dois lineamentos tectônicos identificados através da imagem de satélite (Figura 14 - painel inferior): um de direção N-S na porção mais nordeste e outro de direção NWSE próximo ao centro do perfil.

O primeiro ocorre na estação $30 \mathrm{~m}$ e foi demarcado por uma anomalia vertical condutiva. 
O lineamento localizado próximo ao centro da seção, em $175 \mathrm{~m}$, é o correspondente do afloramento mineralizado. Nesse local ocorre uma anomalia vertical resistiva (Figura 14 painel superior). seção (estação de $350 \mathrm{~m}$ ) pode representar o comportamento anômalo de uma provável continuidade para noroeste do lineamento $\mathrm{NW}$ SE que cruza o perfil B5 a sudoeste (ver quadrado sudoeste demarcado no painel inferior

A anomalia condutiva da porção final da da Figura 14).

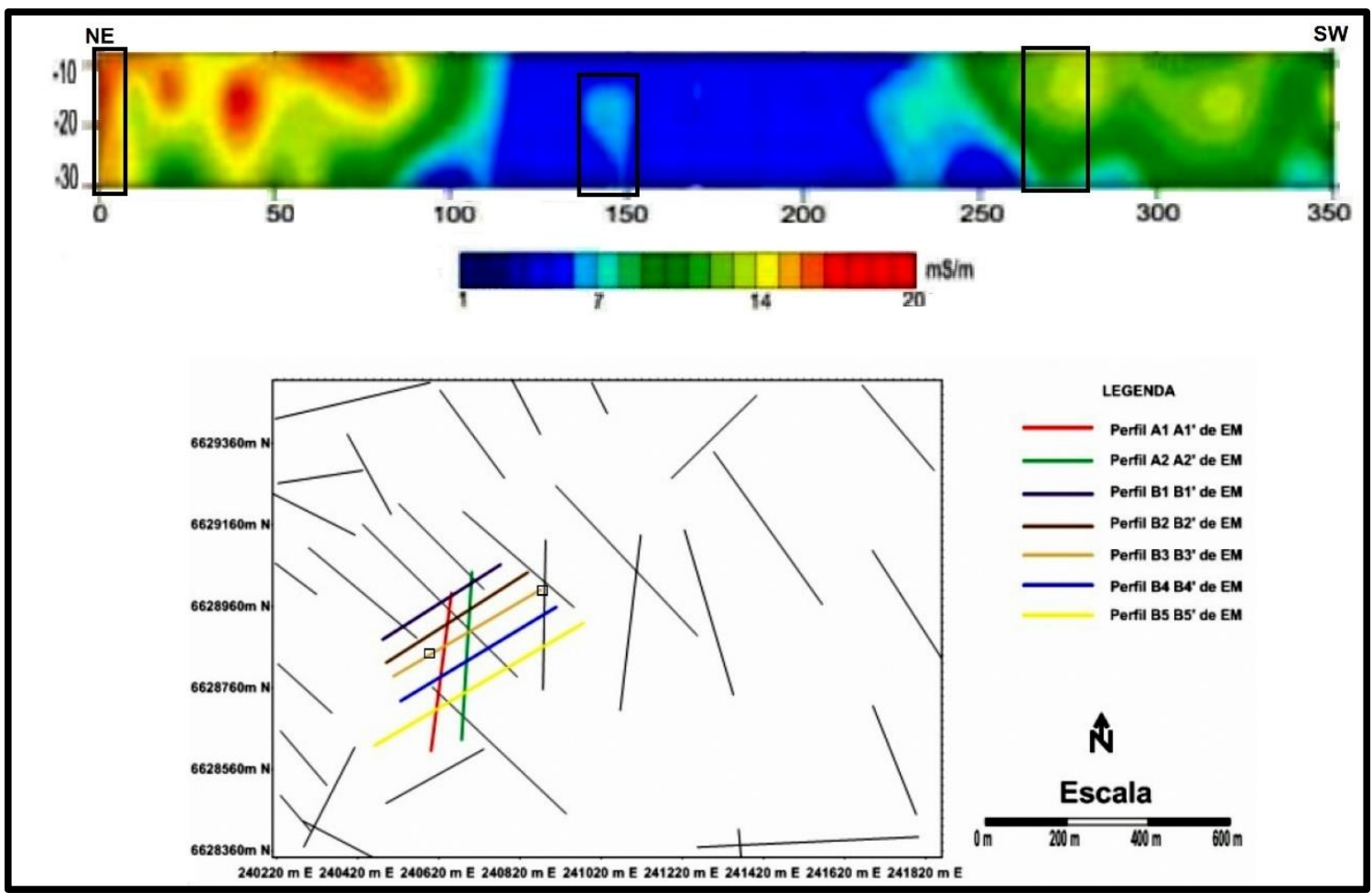

Figura 13 - Pseudo-seção de condutividade aparente do perfil B3 - painel superior; Lineamentos obtidos por sensoriamento remoto com os perfis EM - painel inferior.

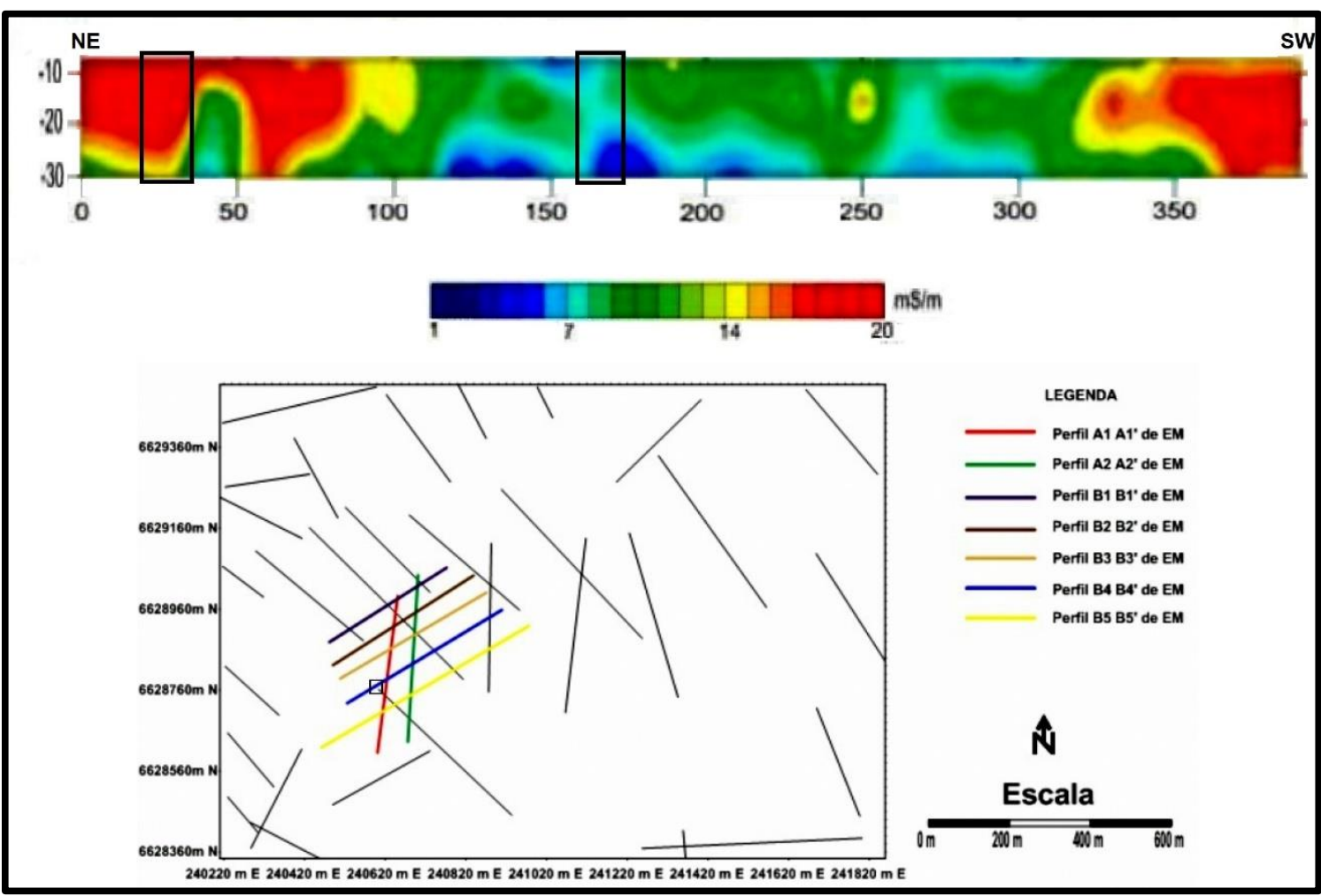

Figura 14 - Pseudo-seção de condutividade aparente do perfil B4 - painel superior; Lineamentos obtidos por sensoriamento remoto com os perfis EM - painel inferior. 
A pseudo-seção de condutividade aparente do perfil NE-SW B5 apresenta domínio de anomalias condutivas (Figura 15 - painel superior). Aparecem dispersas tanto de forma inclinada, como na horizontal e na vertical. Anomalias resistivas aparecem de forma restrita e isoladas em posições próximas à superfície e na base da seção. De acordo com a imagem de satélite, a pseudo-seção de condutividade aparente do perfil B5 cruza um lineamento tectônico N-S e outros dois lineamentos tectônicos NW-SE (Figura 15 - painel inferior).

O lineamento N-S cruza a estação $80 \mathrm{~m}$, que é caracterizada pela ocorrência de anomalia condutiva vertical em profundidade e próximo à superfície apresenta anomalia condutiva de distribuição horizontal. O primeiro lineamento NW-SE ocorre em $170 \mathrm{~m}$ e se refere ao lineamento do afloramento mineralizado. Essa estação é marcada por outra anomalia vertical de elevada condutividade, que se dissemina na base da seção. O último lineamento cruza o perfil em $370 \mathrm{~m}$, onde também ocorrem valores altos de condutividade aparente desde a superfície até a base da seção de forma disseminada (Figura 15 painel superior).

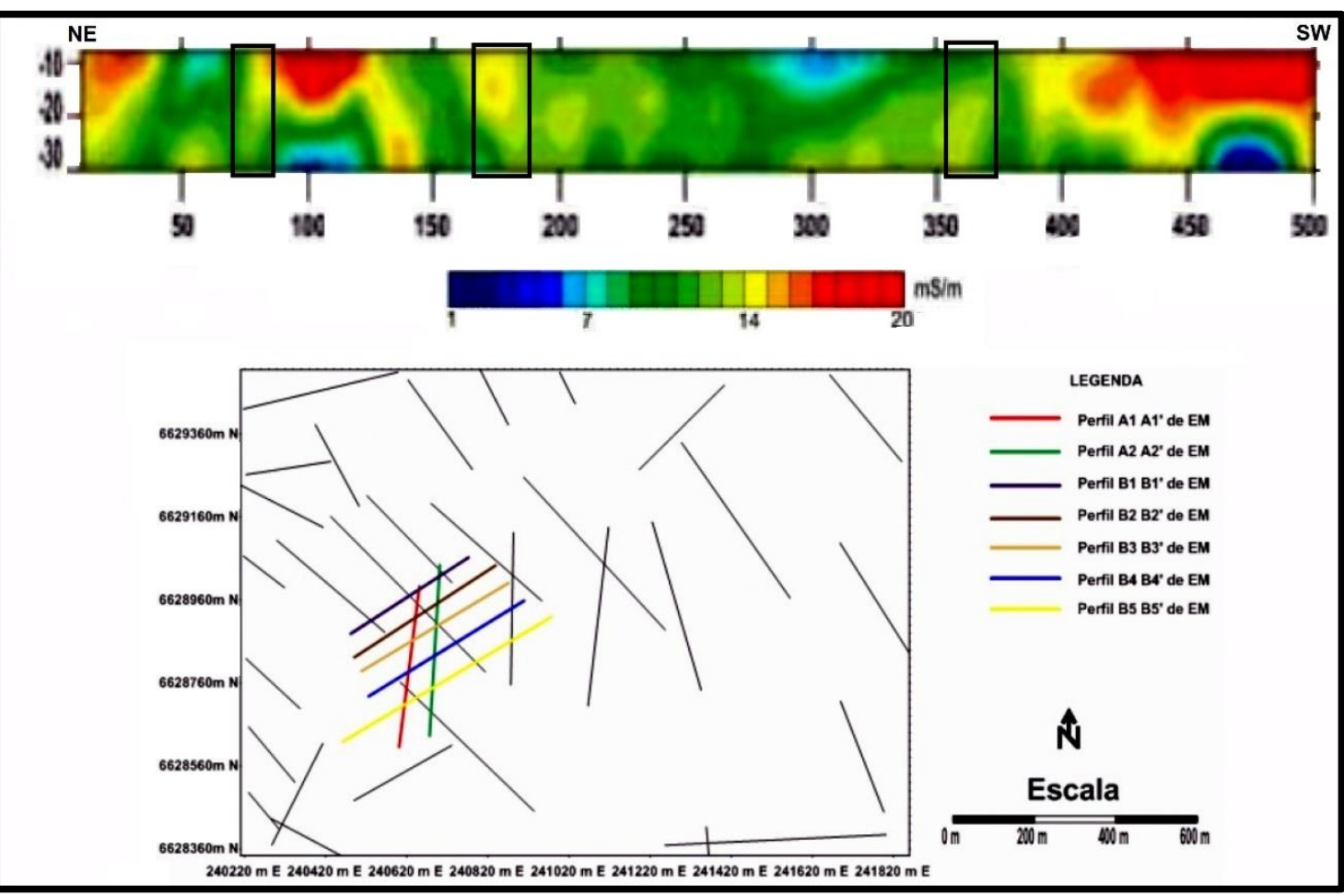

Figura 15 - Pseudo-seção de condutividade aparente do perfil B5 - painel superior; Lineamentos obtidos por sensoriamento remoto com os perfis EM - painel inferior.

A aplicação de dados geofísicos visa essencialmente a determinação de contrastes de parâmetros físicos intrínsecos ao ambiente geológico. A ocorrência cuprífera estudada consiste em impregnações de malaquita entre as foliações e em fraturas de xistos do Complexo Metamórfico Vacacaí. Os xistos mineralizados da ocorrência fazem parte de um bloco de quartzo W-E que se destaca no relevo da área (vide Figura 3). As direções principais dos lineamentos tectônicos obtidos pela análise de sensoriamento remoto e corroborada no levantamento estrutural foram: preferencial para NW-SE e secundária para N-S (vide Figuras $7 \mathrm{e}$ 8).

Esse contexto geológico favorece uma clara observação de contrastes entre propriedades físicas. Os minerais associados aos carbonatos de cobre presentes nos fraturamentos devem apresentar maior condutividade em relação aos minerais constituintes do bloco de quartzo e dos xistos que eles atravessam.

O lineamento tectônico correspondente ao afloramento mineralizado foi atravessado por todos os perfis geofísicos de investigação. Os perfis de direção NE-SW B1 e B5 e o perfil de direção N-S A2 apresentaram anomalias verticais de média a alta condutividade nos locais correspondentes a este lineamento. Todavia, o restante dos perfis NE-SW- B2, B3 e B4 e o perfil $\mathrm{N}-\mathrm{S}$ A1 apresentaram anomalias verticais de média a baixa condutividade para este local. Esta variação de condutividade observada para o lineamento tectônico do afloramento minera- 
lizado é explicada pela influência imposta pelos valores resistivos associados ao corpo de quartzo encaixante.

As respostas de condutividade aparente obtidas nas porções iniciais dos perfis NE-SW B1 e N-S A2 para o lineamento de direção NWSE também foram influenciadas pelo corpo de quartzo. Já o lineamento NW-SE cruzado no extremo sudoeste do perfil NE-SW B1 foi demarcado por uma anomalia vertical de média a alta condutividade. Esta resposta anômala também foi encontrada respectivamente em posições correspondentes nos perfis NE-SW B2 e B3, sugerindo a continuidade desse lineamento para sudeste, além do apresentado pela imagem de satélite.

A única fratura N-S cruzada por perfis eletromagnéticos (NE-SW B4 e B5) apresentou como resposta anomalias verticais de alta condutividade. Tal fato corrobora para que ocorra mineralização em subsuperfície também para esse lineamento tectônico de direção secundária. $\mathrm{O}$ lineamento tectônico cruzado na porção mais sudoeste do perfil NE-SW B5 apresentou como resposta eletromagnética valores médios a altos de condutividade aparente. Esse lineamento também é cruzado pelos perfis N-S A1 e A2 com a mesma resposta eletromagnética. De acordo com a imagem de satélite, o perfil NE-SW B4 não cruza este lineamento, mas em sua posição correspondente foi demarcada uma anomalia vertical de elevada condutividade. Essa evidência sugere que esse lineamento está continuado para norte, além do demonstrado pela imagem de satélite.

Anomalias horizontais demarcadas próximas à superfície e a base das seções associadas às anomalias verticais de elevada condutividade foram entendidas como a disseminação da mineralização.

\section{CONCLUSÕES}

Os resultados obtidos a partir da aplicação do método geofísico eletromagnético indutivo (EM) foram satisfatórios no sentido de possibilitar a delimitação de fraturas com provável mineralização de cobre em subsuperfície na área da ocorrência mineral Victor Teixeira.

$\mathrm{O}$ lineamento tectônico NW-SE correspondente à ocorrência mineral com presença de malaquita foi caracterizado com padrões anômalos verticais variando entre valores baixos a médios e médios a altos de condutividade aparente. As respostas não esperadas de valores médios a baixos de condutividade aparente para a mineralização são explicadas pela provável influência dos valores resistivos associados ao bloco de quartzo e xistos encaixantes. Praticamente todos os demais lineamentos de direções preferenciais NW-SE e o de direção secundária N-S foram caracterizados por anomalias verticais de elevada condutividade aparente.

As anomalias condutivas horizontais caracterizadas próximo a superfície e a base das pseudo-seções, que estavam associadas às anomalias verticais de elevada condutividade, foram interpretadas como a disseminação da mineralização em subsuperfície.
Os resultados dos caminhamentos eletromagnéticos ainda demonstraram que alguns lineamentos de direção NW-SE se prolongam para além do demarcado pela imagem do satélite LANDSAT 5-TM.

A verificação da geologia local e a análise de sensoriamento remoto dos lineamentos tectônicos foram os pilares para o sucesso do estudo por viabilizarem a delimitação dos perfis de caminhamento eletromagnético e a interpretação dos dados geofísicos.

Trabalhos posteriores podem ser realizados para mapeamento e modelamento de todo o corpo resistivo representado pelo bloco de quartzo o qual faz parte $o$ afloramento mineralizado. Sua importância se refere ao fato de que esse corpo parece constituir um sistema do tipo stockwork. Os métodos geofísicos potenciais da gravimetria e da magnetometria são recomendados por serem amplamente utilizados para o mapeamento e modelamento de feições lito-estruturais. Os contrastes físicos esperados para esses métodos seriam de baixa intensidade magnética e elevada densidade para o corpo de quartzo em contraste com a maior intensidade magnética e menor densidade dos xistos do Complexo Metamórfico Vacacaí.

\section{AGRADECIMENTOS}

Os autores agradecem a Pró-Reitoria de Pesquisa, Pós-graduação e Inovação da Universidade Federal do Pampa - UNIPAMPA pela aquisição do equipamento Condutivímetro de Terreno EM34 
XL, obtido por meio de edital de apoio a pesquisa 2009, projeto de registro $\mathrm{n}^{\circ}$ 03.002.09. Agradecemos ainda a empresa Minning Ventures Brasil pela permissão de estudo na área e pela divulgação do trabalho.

\section{REFERÊNCIAS}

BENSON, A.K. \& STUBBEN, M.A. Interval resistivities and very low frequency electromagnetic induction - an aid to detecting groundwater contamination in space and time: a case study. Environmental Geosciences, n. 2, p. 74-84, 1995.

BIZZI, L.A.; SCHOBBENHAUS, C.; VIDOTTI, R.M.; GONÇALVES, J.H. Geologia, Tectônica e Recursos Minerais do Brasil: texto, mapas \& SIG. Brasília: CPRM Serviço Geológico do Brasil, 692 p., 2003.

EPA-ENVIRONMENTAL PROTECTION AGENCY. Use of Airborne, Surface, and Borehole Geophysical Techniques at Contaminated Sites. Washington, cp. 1: 4-6, 1993.

GEONICS. EM-34 \& EM34-3XL. Operating Instructions (for model with two digital meters). Ontario Canada L5T 1C6, 2007.

GOLDEN SOFTWARE INC. SURFER 9 User's guide/Contouring and 3D Surface Mapping for Scientists and Engineers, Software. 2009.

GOLDSTEIN, N.E.; BENSON S.M.; ALUMBAUGH, D. Saline Groundwater Plume Mapping with Electromagnetics. Geotechnical and Environmental Geophysics, Investigations in Geophysics, S.E.G., v. II, n. 5, p. 17-27, 1990.

GREENHOUSE J.P \& SLAINE D.D. Geophysical modelling and mapping of contaminated groundwater around three waste disposal sites in southern Ontario. Canadian Geotechnical Journal, n. 23, p.372-384, 1986.

IBGE-INSTITUTO BRASILEIRO DE GEOGRAFIA E ESTATÍSTICA: Diretoria de Pesquisas, Coordenação de População e Indicadores Sociais. Cidades - Caçapava do Sul, 2018. Disp. em: https://cidades.ibge.gov.br/brasil/rs/cacapava-dosul/panorama. Acessado em: 02/01/2018.

KEAREY, P.; BROOKS, M.; HILL, I. An Introduction to Geophysical Exploration. 3 ed. London: Blackwell Science, 268 p., 2002.
KNÖDEL, K; LANGE, G.; VOIGT, H.J. Environmental Geology: Handbook of Field Methods and Case Studies. Hannover: Springer, 1357 p., 2007.

LANDIM, P.M.B. Introdução aos métodos de estimação espacial para confecção de mapas. DGA, IGCE, UNESP/Rio Claro, Lab. Geomatemática, Texto Didático 02, 20 p., 2000.

McDOWELL, P.W.; BARKER, R.D.; BUTCHER, A.P.; CULSHAW, M.G.; JACKSON, P.D.; McCANN, D.M.; SKIPP, B.O.; MATTHEWS, S.L.; ARTHUR, J.C.R. Geophysics in engineering investigations. London: CIRIA, 252 p., 2002.

McNEILL J. Electromagnetic Terrain Conductivity Measurement at Low Induction Numbers. Geonics Ltd., Ontario, Canadá, Technical Note Tn - 6, p. 15, 1980.

MILSOM, JOHN. Field Geophysics: the geological field guide series. 3. ed. University College London, 232 p., 2003.

MOON, C.J.; WHATELEY, M.E.G.; EVANS, A.M. Introduction to Mineral Exploration. 2. ed. Blackwell Publishing, Malden, 481 p., 2006.

PEREIRA, R. M. Fundamentos de Prospecção Mineral. Rio de Janeiro. Editora: Interciência Ltda, 183 p., 2003

PORCHER, C.A.; LEITES, S.R.; RAMGRAB, G.E.; CAMOZZATO, E. Programa Levantamentos Geológicos Básicos do Brasil. Passo do Salsinho. Folha SH. 22-Y-A-I-4. Estado do Rio Grande do Sul. CPRM, 339 f., 1995.

TELFORD, W.M.W.; GELDART, L.P.; SHERIFF, R.E. Applied Geophysics. 2. ed. London: Cambridge University Press, 751 p., 1990. 